\title{
DESIGN DE SUPERFÍCIE: ESTUDO DE FORMA E DESENHO BIDIMENSIONAL DOS REVESTIMENTOS DA ARQUITETURA MODERNA RESIDENCIAL DE CAMPINA GRANDE - PB
}

Arthur Thiago Thamay Medeiros

Universidade Federal de Campina Grande

thiagothamay@hotmail.com

Alcília Afonso

Universidade Federal de Campina Grande

kakiafonso@hotmail.com

Camilla Thais de Menezes Landim

Universidade Federal de Campina Grande

milla-thais@live.com

Resumo: O presente artigo tem como objeto o Design de Superfície das obras modernas de Campina Grande, sendo usadas como estudo de caso as residências projetadas pelo arquiteto Geraldino Duda. O objetivo é analisar os elementos de design de superfície de tais obras, com foco em sua estrutura morfológica, padrões formais e demais aspectos iconográficos, buscando uma compreensão técnico-construtiva e sua relação com o contexto sociocultural do período estudado, identificando princípios e regras formais, fundamentais do desenho bidimensional inerentes ao âmbito do design de superfície, empenhando-se em esclarecer a predominância de normas na elaboração de tais concepções arquitetônicas. O recorte temporal foi estabelecido entre os anos 1960 1969 por se tratar da década de intenso trabalho do arquiteto, consequentemente, período de grandes mudanças no cenário arquitetônico local. Trata-se de uma pesquisa que dialoga entre conhecimentos das áreas de arquitetura com saberes e metodologias de design, portanto, questões que não forem elucidadas ao longo dos resultados, servirão para futuros desdobramentos deste mesmo trabalho. De inicio, as constatações indagadas neste artigo atuarão como provocador para demais discussões no meio acadêmico sobre o design de superfície das construções arquitetônicas modernas.

Palavras-chave: Design de Superfície, Arquitetura Moderna, Desenho Bidimensional, Patrimônio Moderno, Geraldino Duda

Abstract: This article is about the design surface of modern works of Campina Grande, being used as a case study the residences designed by Geraldino Duda architect. The goal is to analyze the surface design elements of such works, focusing on their morphological structure, formal standards and other iconographic aspects, looking for a technical and 
constructive understanding and its relationship with the socio-cultural context of the period studied, identifying principles and formal rules basic two-dimensional design inherent to the scope of surface design, striving to clarify the prevalence of standards in the preparation of such architectural concepts. The time frame has been established between the years 1960 1969 because it was the decade of intense work of the architect, consequently, major changes period on the local architectural scene. This is a research dialogue between knowledge of the architectural areas with knowledge and design methodologies, so issues that are not elucidated over the results will serve to future developments of this same work. Initially, the inquire findings in this article will act as provocative to other discussions in the academic world on the design surface modern architectural buildings.

Keywords: Surface Design, Modern Architecture, Two Dimensional Drawing, Modern Patrimony, Geraldino Duda

\section{INTRODUÇÃO}

O presente artigo tem como tema o design de superfície da arquitetura moderna de Campina Grande - PB, especificamente, como objeto de estudo as residências unifamiliares projetadas pelo arquiteto Geraldino Duda na década de 1960. O objetivo foi analisar os elementos de design de superfície de tais exemplares modernistas da cidade, com foco em sua estrutura morfológica, padrões formais, princípios fundamentais de desenho e demais aspectos iconográficos, buscando uma compreensão técnico-construtiva e sua relação com o contexto sociocultural do período estudado, identificando princípios e regras formais no âmbito do design de superfície, empenhado em esclarecer a predominância de normas na elaboração das concepções arquitetônicas.

Os objetivos específicos foram, em especial, analisar a conjuntura do período modernista campinense, para que fosse possível reconhecer os elementos morfológicos, culturais e iconográficos do objeto de estudo, a fim de verificar a relação entre o design de superfície e a arquitetura modernista de Campina Grande, como também, descrever o processo de composição formal do corpus de análise. A justificativa em analisar os elementos do design de superfície da arquitetura moderna de Campina Grande, especificamente, as obras do arquiteto Geraldino Duda se faz necessária devido à importância do legado moderno da cidade e a relevância de suas obras na historia urbana e construção social do município.

Através de pesquisas realizadas no próprio acervo do arquiteto e a partir de artigos publicados em anais de eventos e periódicos, pode-se traçar um parâmetro e compreender com mais profundidade a modernidade em Campina Grande e sua importância histórica, bem como o uso de ornamentos em suas obras, que pode ser agrupado em diversas posturas e tal característica pode ser identificada como uma coerência que sintetiza seu estilo em concordância com as demais tradições existentes (TINEM, COTRIM, 2014). 


\section{DESENVOLVIMENTO}

\subsection{Campina Grande e a arquitetura moderna local}

A cidade localiza-se no interior do estado da Paraíba, no agreste paraibano, na parte oriental do Planalto da Borborema, sempre foi referência no comércio varejista, tecnológico e arquitetônico. Fundada em 1697, somente em 1864 foi elevada à categoria de cidade. De acordo com dados de 2014 fornecidos pelo IBGE, sua população é de 402.912 habitantes, sendo a segunda cidade mais populosa do Estado. Sua região metropolitana, formada por dezenove municípios, possui uma população estimada em 630.788 habitantes possuindo atualmente 52 bairros.

Envolvida por uma atmosfera de otimismo e mudanças que permeavam na cidade, em meados da década de 1950 até o final da década de 1970, Campina Grande experimentava o desenrolar de um novo ciclo de modernização, em compasso com os acontecimentos nacionais e alicerçados nos esforços da elite local para inseri-la no processo de industrialização do país (MOREIRA, 2007). Segundo o autor, a influência da arquitetura moderna brasileira deu-se, sobretudo, no que se refere à incorporação da tradição erudita e popular, desempenhando um importante papel na constituição da arquitetura local.

O progresso era notório e a arquitetura modernista imperava as novas construções da cidade: o Teatro Municipal Severino Cabral que em seu projeto original era todo na cor branca, a Escola Politécnica da Universidade da Paraíba em branco, concreto armado e tijolo aparente; e as residências suntuosas de médicos e comerciantes marcaram a história de Campina, pautada em emergência no avanço civil e tecnológico.

No cenário arquitetônico da época, vários profissionais fizeram parte da construção dessa concepção de arquitetura moderna na cidade, como relata Tinem e Cotrim:

[...] vários profissionais vindos de outros lugares, como o arquiteto carioca Ayrton Nóbrega, que fez a primeira proposta para o Teatro Municipal, em 1957, ou como Roberto Burle Marx e o polonês Wit Olaf Prochnik, que foram contratados para elaborar o projeto de urbanização do Açude Velho na década de 1950, também passaram pela cidade nesse mesmo momento. Concomitantemente, alguns engenheiros campinenses ou radicados no município, como Lynaldo Cavalcante, Austro de França Costa, Max Hans Karl Liebig, Giusepe Gioia e Glauco Benévolo, e desenhistas, como Anacleto Eloi, Walter Cordeiro de Lima, Adelgício Lima Filho e Geraldino Pereira Duda, começaram a se engajar nesse movimento de renovação arquitetônica (TINEM, COTRIM, 2014, p. 86).

Princípios formais desse estilo arquitetônico tornaram-se modismo, difundindose por toda a cidade, às vezes de maneira esteticamente equivocada. MOREIRA (2007) descreve o decênio de 1960 como o período de renovação arquitetônica da Rainha da Borborema, com a filiação de boa parte dos edifícios construídos na cidade ao Movimento de Arquitetura Moderna, ainda que muitas vezes de maneira incompleta, superficial, ou incorporando apenas elementos isolados dessa linguagem. Linhas funcionais, valorização da climatização natural, predominância volumétrica e revestimentos variados formavam a execução das obras: módulos vazados, cerâmicas, azulejos e tacos compunham os pisos e paredes do conjunto arquitetônico moderno. 


\subsection{O arquiteto Geraldino Duda}

Geraldino Pereira Duda, natural de Campina Grande onde reside até os dias atuais, nasceu no dia 06 de março de 1935. Desde pequeno sempre teve gosto por trabalhos manuais e pela leitura, ponto de partida de onde surgiu o gosto pela arquitetura ao observar os trabalhos do arquiteto Oscar Niemeyer.

Seu extenso trabalho começou na década de 1950 no escritório do arquiteto Josué Barbosa Pessoa. Já nos anos de 1960, tornou-se assistente técnico de arquitetura e urbanismo do departamento de planejamento e urbanismo da PMCG. Foi então que, em 1962 começou a elaborar o projeto do Teatro Municipal Severino Cabral, obra que o deu grande destaque e prestigio. Primeiramente, o teatro estava planejado para cobrir apenas o centro do terreno onde hoje se encontra. No entanto, surgiu a ideia de construí-lo no formato de um instrumento musical, pois no teatro há música e música inspira arte. Com isso, a volumetria do teatro foi inspirada em um apito ou bico de flauta. Sua arquitetura moderna tem inegável importância histórica, artística e patrimonial para a cidade e região. (TEATRO, 2016).

Em entrevista, o arquiteto declara que nos anos 1960, ele se limitava a realizar projetos arquitetônicos, ficando a construção sob responsabilidade do engenheiro e só após os anos 1980, quando seu diploma de engenharia foi expedido, passou a participar de todo o processo, desde a elaboração do projeto até a construção (FREIRE, 2010). Apesar de ter iniciado seus trabalhos na década de 1950, é fascinante o grande numero de projetos residenciais unifamiliares que foram produzidos nos anos 1960, contabilizando 46 casas no total, chegando a fazer três projetos em um mês. Coletados tais dados, julgou-se importante verificar as obras deste decênio de grande produção, onde famílias de médicos, cientistas políticos, comerciantes e profissões de alta renda sentiram-se incitadas a construir residências suntuosas e diretamente ligadas ao estilo de arquitetura que imperava em todo o Brasil, mesmo que tardiamente em Campina Grande.

\subsection{Metodologia}

A pesquisa se desenvolveu seguindo métodos qualitativos, onde serão usados dois exemplares modernistas do município projetados por Geraldino Duda, mapeando e registrando a produção em questão. Foram observados os elementos do design de superfície, explorando o universo dos significantes e significados, dos motivos e aspectos visuais que foram abordados de maneira descritiva. CRESWELL (2007) afirma que a técnica qualitativa é aquela que o investigador sempre faz alegações de conhecimento com base principalmente ou em perspectivas construtivistas (ou seja, significados múltiplos das experiências individuais, significados social e historicamente construídos, com o objetivo de desenvolver uma teoria ou um padrão). Ela também usa estratégias de investigação como narrativas, fenomenologias, etnografias, estudos baseados em teoria ou estudos de teoria embasada na realidade.

Em relação aos objetivos em questão da pesquisa, quanto à contextualização do design de superfície, classificamos como experimental com estudo de caso. Nesse sentido, a pesquisa experimental consiste essencialmente em determinar um ou mais objetos de estudo, selecionar as variáveis capazes de influenciá-lo e definir as formas de controle e de observação dos efeitos que a variável produz no objeto. Trata-se, 
portanto, de uma pesquisa em que o pesquisador é um agente ativo, e não um observador passivo (GIL, 2008). Partindo da perspectiva do autor, onde afirma que o estudo de caso consiste na análise profunda e exaustiva de um ou poucos objetos, de maneira que permita seu amplo e detalhado conhecimento.

$\mathrm{Na}$ abordagem das interpretações, será utilizado o conceito de recepção direta. MOREIRA (2007) classifica a recepção direta quando o autor obteve as informações a partir do contato direto com a obra, ou seja, a recepção está ligada a interpretação. É importante que seu planejamento seja flexível, de modo que possibilite a consideração de variados aspectos relativos ao estudo de caso, construindo hipóteses através de levantamento bibliográfico, análise de registro fotográfico e pesquisa de campo.

\subsection{O design de superfície nas obras de Geraldino Duda: estudo de duas residências unifamiliares}

Para que fosse possível traçar os elementos comuns a respeito dos princípios utilizados por Geraldino Duda na concepção do design de superfície de suas obras, foram selecionadas duas residências que permaneceram parcialmente ou sem quaisquer reconfigurações estruturais e formais até os dias atuais.

O intuito é investigar os elementos em que houve intervenção sistemática ou empírica na área do design de superfície, bem como seus padrões cromáticos, aplicação e linguagem iconográfica, resgatando a identidade local de um patrimônio urbano, partindo do pressuposto do design como comunicador, explorando seu caráter sistemático e significativo. Sobre a elaboração e composição das formas e dos desenhos bi e tridimensionais, Wong (2010) descreve o uso de dois tipos de abordagem: intuitiva, quando traços ou formas ocorrem espontaneamente à medida que se explora instrumentos, meios ou substancias para obter efeitos pictóricos, escultóricos ou de textura e, neste processo, decide-se o que é interessante sem ter consciência, tendo como tomada de decisão gostos e inclinações pessoais; e intelectual, quando se cria reconhecendo previamente os problemas específicos que precisam ser tratados, definindo metas e limites, analisando as situações e escolhendo os elementos para síntese, tentando propor soluções mais apropriadas. Ainda sobre o desenho bi e tridimensional, o autor conceitua os princípios de radiação, gradação, similaridade, contraste, repetição e concentração como elementos fundamentais na composição das formas.

Ruthschilling (2008) enxerga o Surface Design como um tema relativamente novo no Brasil e pouco tratado em nível de graduação e pós-graduação. No entanto, o Conselho Nacional de Desenvolvimento Científico e Tecnológico (CNPq), passou a integrar em 2005 este segmento de design como uma especialidade, o que, segundo a autora, trará mais visibilidade e respaldo para discussões nesse âmbito. Segundo a autora, os padrões desenvolvidos, além da função de ornamentar, estabelecem um diálogo entre o contexto onde estão inseridos através dos motivos, simbolismos e informações que trazem consigo. Rubim (2010) afirma que o design de superfície pode ser representado por diversas maneiras e em produtos distintos, e ratifica dizendo que, além de poder ser aplicada em várias áreas do design, também se refere a design de revestimento, e para sua concepção, é necessária a utilização de técnicas específicas. 
Na pesquisa, utilizou-se a abordagem de cunho representacional descrita por Schwartz (2008), onde envolve a geometria e a representação gráfica do objeto em análise. Portanto, trata-se de um trabalho focado em coletar, legitimar e possibilitar uma percepção aprofundada acerca de um período baseado em intensas mudanças espaciais. Para elucidar tais questões é importante ir além dos campos da história, arquitetura ou antropologia. Tais ciências serão utilizadas como instrumentos auxiliares, que possibilitarão promover uma compreensão diante do repertório extraído de um patrimônio relevante. Os motivos impressos em cerâmicas, azulejos, e outros elementos (icônicas no campo da semiologia e semiótica), nos dão pistas e incitam o aprofundamento das questões levantadas.

Ao analisar as duas edificações postas em análise, verificou-se que ambas apresentam características bastante semelhantes em suas superfícies, aspectos estruturais e formais de suas construções: localizam-se em terrenos de topografia com inclinação que possibilita o trabalho com níveis diferentes; parte das casas possui uma área suspensa sustentada por pilotis, geralmente abrigando as garagens; o uso do concreto armado muito difundido na época; o traçado em linhas geométricas, retas ou curvas, valorizado pelas esquadrias; o uso de diferentes materiais e elementos arquitetônicos trabalhando com diversas texturas.

\subsubsection{Residência Antônio Diniz Magalhaes (1968)}

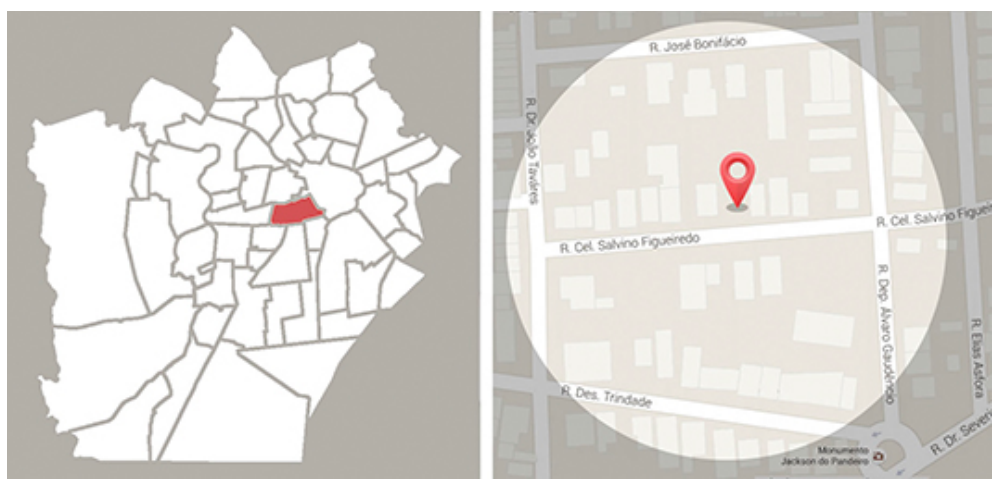

Figura 1- Mapa dos bairros e localização da rua onde se encontra a residência.

Fonte: google.com/maps.

Segundo informações contidas na planta-baixa original, a residência possui área de $227 \mathrm{~m}^{2}$ e ocupa um terreno de $872,50 \mathrm{~m}^{2}$. Encontra-se fora da poligonal de tombamento proposta pelo IPHAEP e pela Prefeitura Municipal, porém, não sofreu modificações em sua estrutura e superfícies. Foram analisados apenas os elementos de design de superfície da fachada e das áreas externas, pois não foi possível acessar o interior da casa que se encontra posta para venda.

Uma característica marcante em seus projetos é a utilização de padrão cromático contrastante, como forma de dar destaque aos planos e promovendo a movimentação visual das superfícies.

$\mathrm{Na}$ fachada da lateral direita, Geraldino Duda inseriu vigas com revestimento em pastilha de cerâmica nas cores azul e amarelo. Na garagem os pilotis quebram a monotonia, onde a rampa e escada interliga o exterior ao interior. 


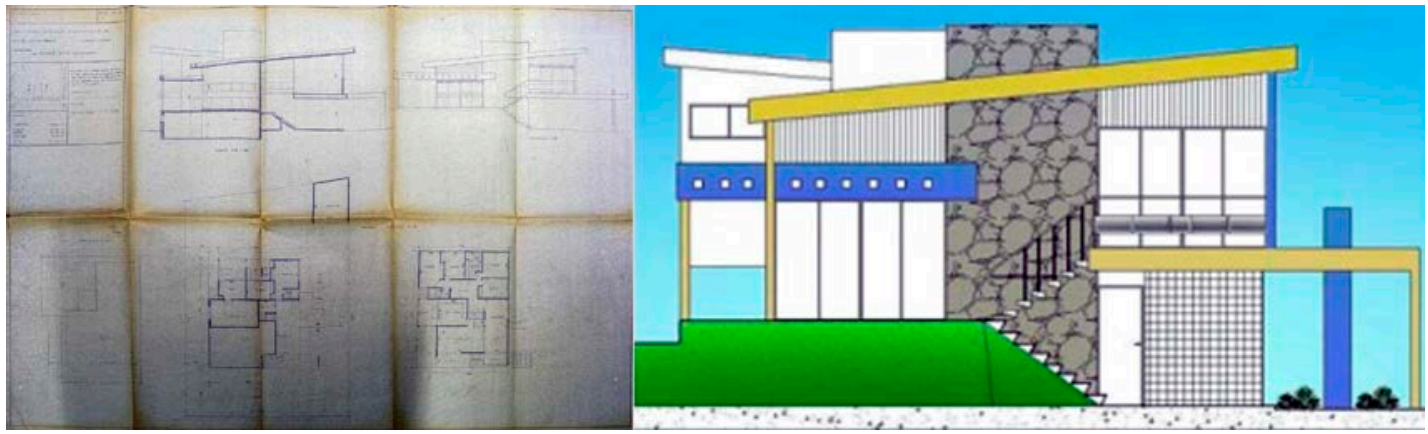

Figura 2 - Planta-baixa da residência e maquete digital. Fonte: Thaís Carvalho e Thaíse Gambarra.

\subsubsection{Tectonicidade}

O edifício possui janelas contínuas em madeira e cobertura de laje inclinada, comum em outros projetos do arquiteto. Pela espessura, é uma nova versão de platibanda, recurso muito utilizado em casas desse período. As paredes externas, ora cobertas por mosaicos de pedra, ora por pastilhas cerâmicas, contrastam com a madeira das janelas e a grande porta em vidro e alumínio da varanda. Em seus projetos, as escadas costumavam ser de mármore branco fosco. Os revestimentos apresentam diferentes texturas pelo uso de tinta fosca, pisos cimentícios e pedras calcárias extraídas da própria região.

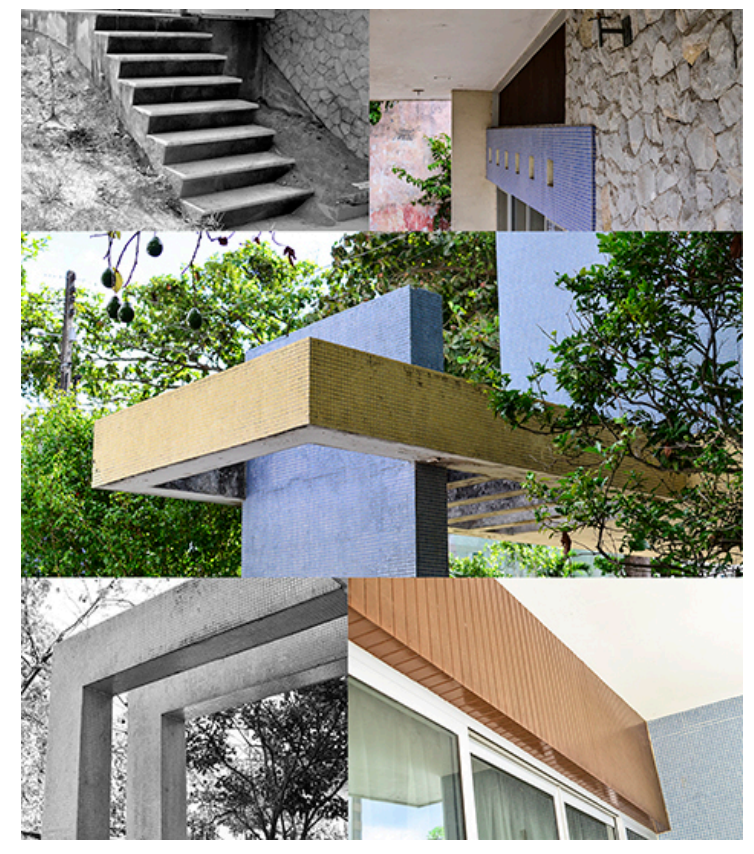

Figura 3 - Detalhes das áreas externas da residência. Foto: Medeiros, A. T. (2016).

O grande painel da garagem foi pintado pelo artista Jair Rodrigues de Recife PE. A pintura contrasta com os azulejos em tons dourado e cor preta, expressando a suntuosidade e sofisticação deste revestimento. A variedade de materiais usada pelo arquiteto e a geometrização dos volumes é uma característica dos seus projetos. 


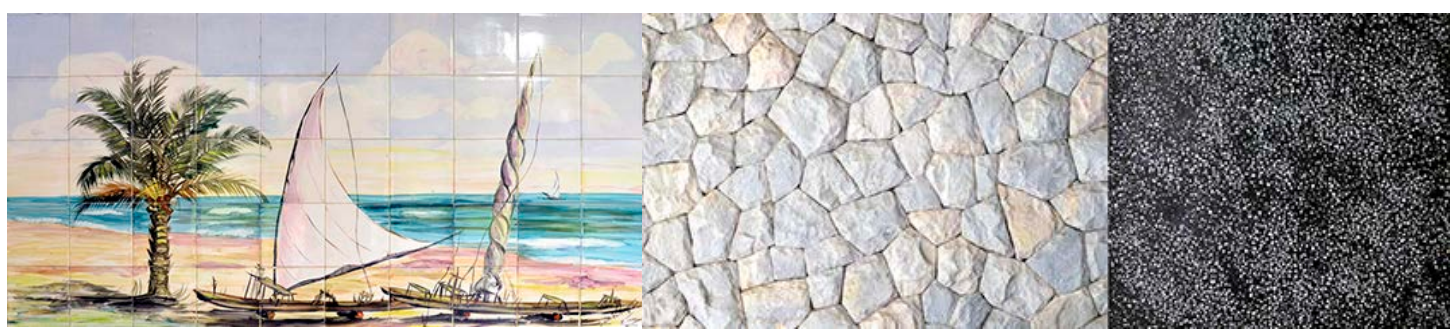

Figura 4 - Detalhe do revestimento pétreo, cimentício e do painel pintado à mão.

Foto: Medeiros, A. T. (2016)

O padrão modular dos azulejos contém vários elementos e grafismos que formam desenhos com motivos florais e rosáceas de expansão. O padrão de gradação segue a lógica de um tabuleiro de xadrez, seguindo uma trajetória alinhada em fileira inter-relacionando com o elemento ao seu lado. O movimento concêntrico que tais elementos exercem no módulo pode ser observado em seu ápice em forma de cruz.
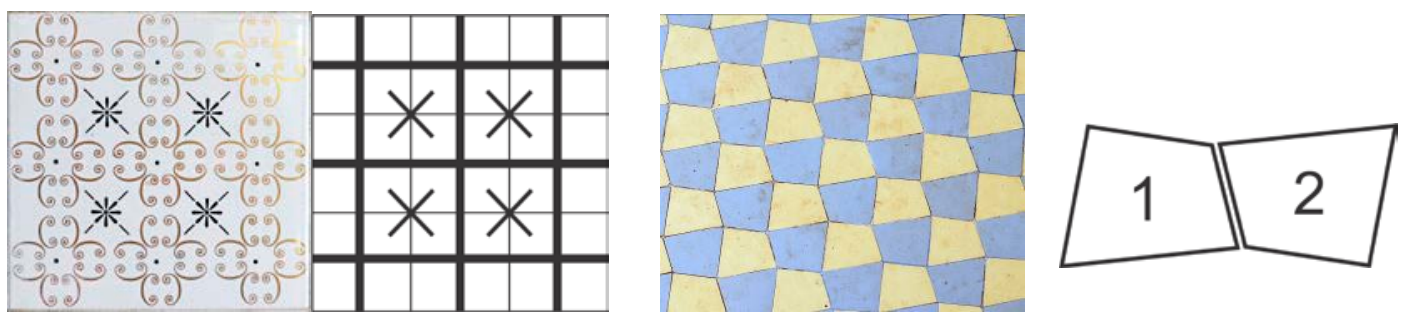

Figura 5 - Detalhe dos revestimentos e seus esquemas de composição.

Foto: Medeiros, A. T. (2016)

O módulo acima à direita é encontrado no revestimento aplicado no piso da varanda principal da residência. Sua forma trapezoidal totalmente assimétrica gera um encaixe rematado na composição. No exemplo de montagem da composição descrito acima módulo 2 é a gradação com espelhamento horizontal e vertical do módulo 1, gerando assim similaridade e uma continuidade. $O$ contraste dado pelas cores distintas reforça a assimetria da forma.

\subsubsection{Residência Aderson Costa Gomes (1964)}
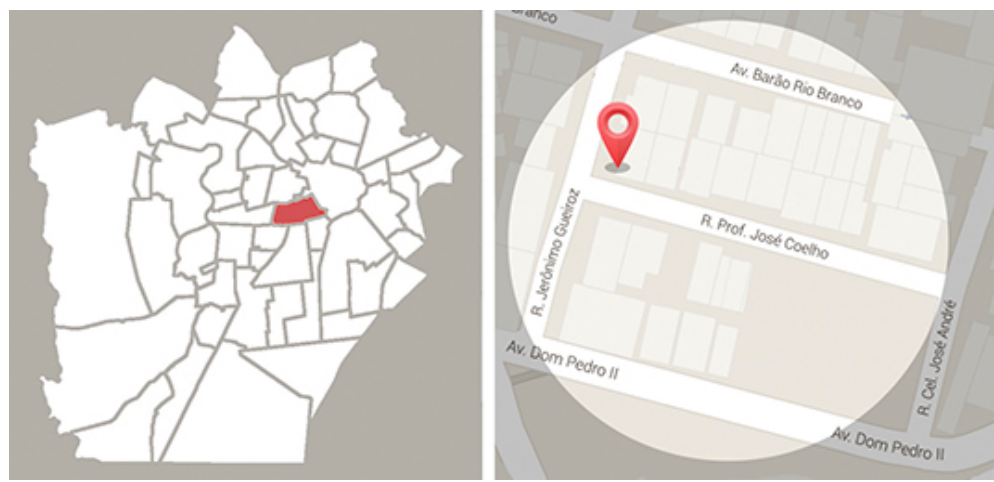

Figura 6 - Mapa dos bairros e localização da rua onde se encontra a residência.

Fonte: google.com/maps 
A residência construída em julho de 1964, está localizada no Centro da Cidade, na Rua Professor José Coelho, n. 128, esquina com a Rua Jerônimo Queiroz. Sua arquitetura chama a atenção devido à monumentalidade do edifício abrigado no lote, de traços diagonais em meio às árvores de seu jardim. Também se encontra fora da poligonal de tombamento proposta pelo IPHAEP e pela Prefeitura Municipal e por isso sofreu modificações no muro e na parte inferior interna que hoje abriga uma clínica. Com o decorrer dos anos, a residência sofreu alterações nos muros, no piso interno de ladrilho hidráulico que foi substituído por um piso cerâmico.

Analisando as plantas da residência, o arquiteto nos dá pistas sobre sua linha de pensamento acerca do design de superfície de suas obras. Percebe-se que no ato de projetar, o arquiteto já compunha suas superfícies com detalhamento preciso.

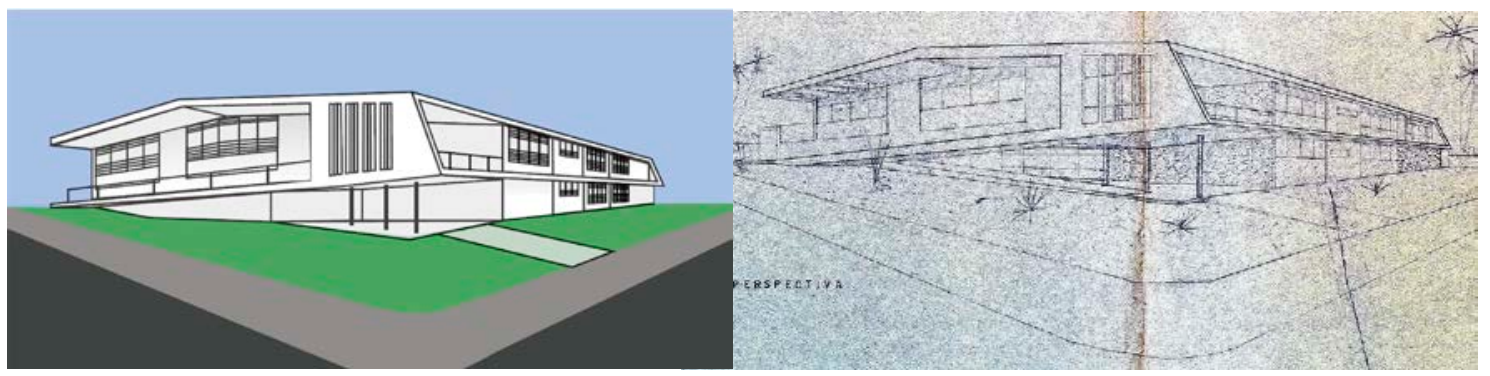

Figura 7 - Perspectiva da residência baseada na planta-baixa original. Fonte: Agharad e Juliana (2016)

A volumetria da residência é resultado de subtrações em um prisma retangular, desenhando cortes de traços diagonais bem marcados no volume do pavimento superior, e denotam certa leveza na área suspensa por pilotis, contrastando com a robustez da sua forma. O plano horizontal é definido pela platibanda e pela marquise vazada em sua fachada frontal, além dos elementos de esquadrias. A simplicidade da forma se soma à riqueza de texturas gerada pelo uso de diferentes materiais, ao ritmo conferido pela repetição de elementos, aos jogos de luz e sombras das pérgulas e cobogós e à sua interação com o jardim externo e a rua.

\subsubsection{Tectonicidade}

O edifício é sustentado por estrutura composta de pilotis, lajes e parede estrutural em concreto armado e alvenaria em tijolo cerâmico. A laje do pavimento superior acompanha a forma da edificação, determinada pela altura da empena, observada tanto por fora, quanto no interior do edifício. As grandes portas e janelas são em madeira e vidro, com bandeiras que se estendem, em sua maioria, até o teto. Além disso, a entrada da luz natural é estimulada pelo uso comum de pérgulas e cobogós. A escada de mármore se apoia em apenas uma de suas laterais, na parede, encontrando-se, portanto, em balanço. Os guarda-corpos que acompanham a rampa, as escadas e protegem a varanda são metálicos (possuindo, esse último, fechamentos em vidro). O revestimento apresenta diferentes texturas pelo uso de tinta fosca, pastilha cerâmica e pedras. 


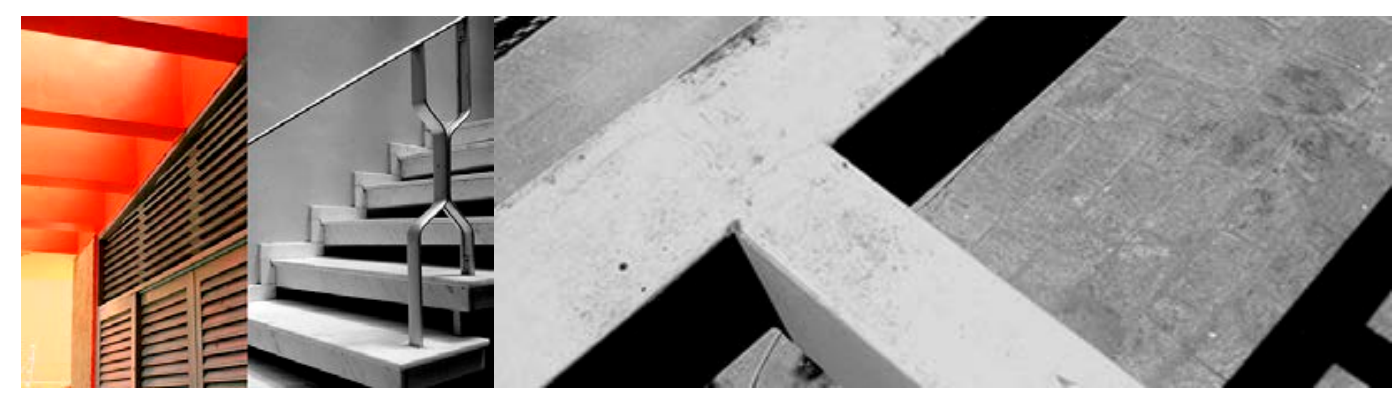

Figura 8 - À esquerda: Janelas da fachada lateral direita acompanhando o desenho inclinado da laje. À direita: detalhe da escada em mármore branco com estrutura de metal. Abaixo: detalhe da marquise vazada da fachada.

Fonte: Agharad e Juliana (2016).

O modelo de cobogó esmaltado fabricado pela Indústria Manufatti nomeado de Vintage, amplamente utilizado nos anos 1950 e 1960 em construções modernas, possui formas orgânicas e assimetria horizontal e vertical. A tridimensionalidade da forma é vista pelos relevos no produto que dão volume e profundidade ao produto. 0 principio da Gestalt de continuidade e similaridade é perceptível nas curvas harmônicas das elipses assimétricas que compõe a forma do cobogó.

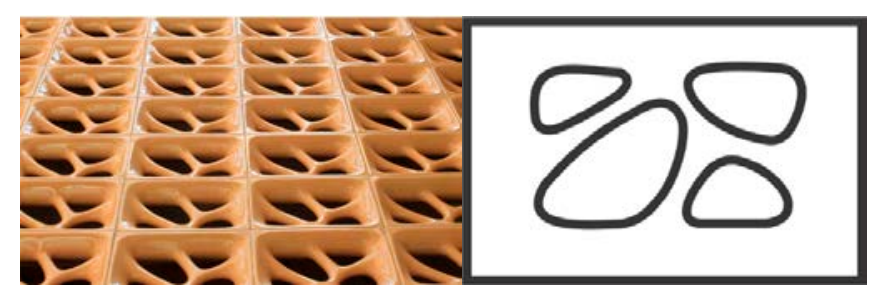

Figura 9 - Fotografia dos cobogós da residência em sala intima que dá acesso aos quartos. Ao lado, imagem bidimensional do cobogó.

Imagens: MEDEIROS. A. T., Agharad e Juliana (2016)

A porta principal de acesso à residência de madeira e vidro gera um contraste interno de luz e sombra na sala de estar. Nos blocos de madeira, há elementos vazados que auxiliam na ventilação do ambiente, tornando o design funcional do projeto desta porta. Por fora, o vidro reflete a paisagem urbana e por dentro, o efeito sensorial é de amplitude e similaridade nas unidades que compõem o todo.

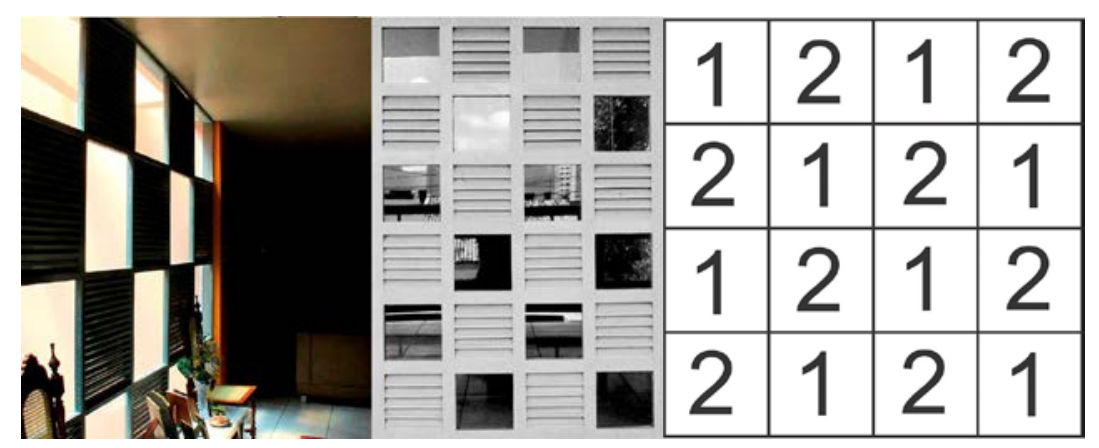

Figura 10 - Imagem frontal da porta principal e o efeito de luz no interior na sala. Ao lado: Sequência da composição dos módulos que compõem a porta.

Imagens: MEDEIROS. A. T., Agharad e Juliana (2016). 
As estruturas ativas formais de repetição dos módulos em grade básica gera a sensação de continuidade em variação de repetição múltipla, denominado de movimento paralelo, onde as unidades de forma são dispostas gradualmente por meio de passos paralelos. Seu ápice é visualmente em linha reta que representam os módulos variáveis de gradação e cada zona contém unidades de forma de mesmo passo.

\section{CONCLUSÃO}

Após observar a produção do design de superfície da arquitetura modernista do arquiteto Geraldino Duda através dos dois exemplares aqui tratados, pode-se perceber algumas peculiaridades:

a) a variedade de revestimentos e materiais utilizada pelo arquiteto o difere dos demais arquitetos de sua época que optavam por tons mais sóbrios e pelo brutalismo dos materiais e superfícies;

b) a plasticidade das obras se caracterizou pelo uso das pastilhas cerâmicas e pedras calcárias em pilares, lajes e paredes, marcando o cenário dos locais nas quais as mesmas estão inseridas;

c) houve todo um rigor metodológico na concepção do design de superfície das obras seguindo os princípios fundamentais de forma e desenho bidimensional;

d) o arquiteto soube tirar proveito dos materiais eleitos para as superfícies utilizando revestimentos encontrados na própria região;

e) A interdisciplinaridade entre conhecimentos que dialogam entre a arquitetura e o design auxiliaram na efetivação da pesquisa, observando o design de superfície sob o viés dos princípios fundamentais que regem o desenho bidimensional presente em todas as superfícies das residências analisadas.

Devido a limitações de dimensão impostas para este artigo, só foi possível analisar duas residências. Porém, o mesmo nível de analise pode ser feito em outras obras como maneira de complementar a pesquisa.

O presente trabalho não conclui nem encerra as discussões sobre o tema, mas contribui divulgando a existência desse acervo para que as pessoas tomem conhecimento do legado moderno da cidade.

\section{REFERÊNCIAS}

ALMEIDA, Adriana. Arquitetura moderna residencial de Campina Grande: registros e especulações (1960-1969). Trabalho de Conclusão de Graduação. João Pessoa, CAU/UFPB, 2007.

CRESWELL, John W. Projeto de pesquisa: métodos qualitativo, quantitativo e misto. 2. ed. Porto Alegre: Artmed, 2007.

FREIRE, Adriana Leal de Almeida. Modernização e modernidade: uma leitura sobre a arquitetura moderna de Campina Grande (1940-1970). Dissertação (Mestrado Programa de Pós-Graduação em Arquitetura e Urbanismo). Escola de Engenharia de São Carlos da Universidade de São Paulo, 2010.

FREITAS, R. O. T. Design de Superfície. As ações comunicacionais táteis nos processos de criação. 1 ed. Blucher, 2011. 
GIL, Antônio Carlos. Como elaborar projetos de pesquisa. 4.ed. São Paulo: Atlas, 2008. GURJÃO, Eliete de Queiroz. Imagens Multifacetadas da História de Campina Grande. Campina Grande: Prefeitura Municipal/Secretaria da Educação, 2000.

MOREIRA, Fernando Diniz. Arquitetura moderna no norte e nordeste do Brasil: universalidade e diversidade. Recife: FASA, 2007.

PMCG. Memorial Urbano de Campina Grande. A união, 1996.

RÜTHSCHILLING, Èvelise Anicet. Design de Superfície. Editora da UFRGS. Porto Alegre, 2008.

SCHWARTZ, A. R. D. Design de superfície: por uma visão projetual geométrica e tridimensional. Dissertação (Mestrado em Desenho Industrial) - Universidade Estadual Paulista, 2008.

TEATRO Municipal Severino Cabral. Disponível em < http://teatroseverinocabral.art.br/>. Acesso em 22 março 2016.

TINEM, Nelci. Desafios da Preservação da arquitetura moderna: o caso da Paraíba. Revista do PPG-AU/UFBA. Salvador, 2010.

TINEM, Nelci. COTRIM, Márcio. Urdidura da modernidade. Arquitetura Moderna na Paraíba I. João Pessoa: Editora Universitária PPGAU/UFPB, 2014.

WONG, Wucius. Princípios de Forma e Desenho. São Paulo: WMF Martins Fontes, 2010. 